\title{
Would Bring Your Own Device (BYOD) be welcomed by undergraduate students to support their learning during fieldwork?
}

Article

Accepted Version

Welsh, K. E., Mauchline, A. L., France, D., Powell, V., Whalley, W. B. and Park, J. (2018) Would Bring Your Own Device (BYOD) be welcomed by undergraduate students to support their learning during fieldwork? Journal of Geography in Higher Education, 42 (3). pp. 356-371. ISSN 1466-1845 doi: https://doi.org/10.1080/03098265.2018.1437396 Available at https://centaur.reading.ac.uk/74752/

It is advisable to refer to the publisher's version if you intend to cite from the work. See Guidance on citing.

To link to this article DOI: http://dx.doi.org/10.1080/03098265.2018.1437396

Publisher: Taylor \& Francis

All outputs in CentAUR are protected by Intellectual Property Rights law, including copyright law. Copyright and IPR is retained by the creators or other copyright holders. Terms and conditions for use of this material are defined in the End User Agreement. 


\section{CentAUR}

Central Archive at the University of Reading

Reading's research outputs online 
Would Bring Your Own Device (BYOD) be welcomed by undergraduate students to support their learning during fieldwork?

\subsection{Introduction}

The Bring Your Own Device (BYOD) concept has numerous definitions in different contexts but essentially, it is the idea that an individual makes use of their personally owned technological device in a workplace or educational setting rather than using an institution owned device to perform work or education related tasks. As outlined by Santos (2013), BYOD is not a new concept; personally owned laptops for example have been used in classrooms and workplaces since the late 1980's (diFilipo, 2013). However, the rise of mobile technologies, particularly smartphones and tablets in the last decade (Afreen, 2014), has been a key driver in the current move towards BYOD both in classrooms (Alberta Education, 2012), field settings (e.g. Welsh \& France, 2012) and multi-national corporations (Afreen, 2014). Whilst there is a growing trend for BYOD in the workplace, Murphy (2013) argues that it is educational institutions that are at the forefront of BYOD adoption and is gaining pace in education (Johnson, 2012). Indeed, Welsh \& France (2012) state that "consideration should be given to encouraging students to use their smartphones in formal educational settings such as the classroom or in the field in order to aid their learning" (p.48). In academic settings, Santos (2013) states that "the basic idea behind the BYOD model is that students will use their own mobile devices to support teaching and learning" (p.1585). The key distinction between the idea of BYOD and that of mobile learning (m-learning) is that while all the benefits of $\mathrm{m}$-learning such as ubiquity, convenience, localisation and personalisation (Parsons and Ryu, 2006) apply to BYOD, the student retains ownership of the device and access to the data collected. Mobile learning via mobile devices is useful for students participating in fieldwork because it allows students to make the best use of their limited time in the field. For example, rather than just collecting data, mobile devices could enable students to begin data analysis in the field and help to identify gaps in the data. BYOD could be a helpful extension of this as it allows students to select their preferred apps and devices which thereby enables flexible (Peat and Franklin, 2002), personalised (Van Harmelen, 2006) 
1 learning. Steiner (2016) outlines how BYOD was expected to become a common practice in "first world" higher education institutes. However, it is worth mentioning that the debate about whether to use BYOD or institutional devices will not be relevant in all countries or institutions, indeed many countries and institutions will make the best use of any devices available to them.

\subsection{Identified educational benefits of BYOD}

Recent research into BYOD in a classroom setting undertaken by Miller \& Welsh (forthcoming) has indicated that not only can students garner all of the benefits of mobile learning, they can further benefit from the familiarity of their own device compared to an institutional device as they can spend their own time learning how the device and applications work. NUS (2010) has also found that students perceive the technology used in Higher Education to be out-dated, a problem which may be circumvented with using their own, potentially more up to date, devices.

There has been an increase in the use of BYOD in a classroom setting and various studies (e.g. Fang, 2009; Conole et al., 2008) have outlined the benefits and challenges of using BYOD in that setting. The perceived educational benefits of implementing BYOD include saving time during the teaching session (Bedall-Hill, 2011), saving the department or the institution money (Welsh \& France, 2012), student familiarity with devices (Ballagas et al., 2004), student's ability to personalise the devices to suit their own learning (Swan et al., 2005) increase of blended learning in classroom settings (Pfoutz, 2012), the ability for students to retain their own data (France et al., 2013; Grant \& Basye, 2014) and studies indicate that using mobile devices may increase motivation and engagement (Swan et al., 2005).

\subsection{Challenges associated with implementing BYOD}

In addition to the perceived educational benefits of BYOD, there are a number of challenges associated with implementing BYOD. Some of the perceived challenges associated with BYOD in a classroom environment have been outlined by Santos (2013). They include: 
1. The need for good network connectivity

2. The importance of network security when connecting student devices to the university Wi-Fi

3. Increased IT support is a requirement of BYOD

4. Disruption in the classroom (i.e. distraction rather than disruptive technologies)

5. Inequality between students (difference device capabilities)

Whilst research into the impacts of using BYOD in school classroom or higher education lecture settings is beginning to gather pace, virtually no research into the applications of BYOD outside of a traditional 'classroom' setting (e.g. in a laboratory or in fieldwork) has been undertaken. Fieldwork is a core part of numerous studies including geography, biosciences and archaeology. A number of studies have demonstrated the effectiveness of fieldwork (Kern \& Carpenter, 1984; 1986, Fuller et al., 2006, Boyle et al., 2007, Maskall \& Stokes, 2008). More recently, a number of studies have shown the suitability of using mobile devices for fieldwork to enhance the student learning experience (France et al., 213, France et al., 2016, Fletcher et al., 2007, Jarvis \& Dickie, 2010, Welsh et al., 2015). Welsh et al. (2015) outline the suitability and learning potential of mobile devices for use within fieldwork and describe the "urgent need to explore BYOD as a possibility for fieldwork" (p.18). Investigating the possibility of BYOD for fieldwork seems like a natural progression from supplying students with institution-owned mobile devices to encourage the use of personalised, student-owned devices in the field for those subjects that engage with fieldwork activities. Whilst the concerns associated with BYOD in a classroom are well documented (c.f Santos, 2013), whether these concerns are the same for BYOD in a field setting is as yet untested and will therefore be explored within this research.

Numerous studies have outlined that almost all students now entering Higher Education own their own devices (Sainsburys Bank, 2014). However, despite owning the device, another factor which could be problematic when implementing BYOD into a teaching session is the level of student willingness to use their own mobile device. Previous studies have shown that the majority of 
1 students are already using their own mobile devices for learning or are willing to use their own

2 device. For example, Woodcock et al. (2012) found that $47 \%$ of students surveyed used their own

3 devices to support learning whilst Lerczak (2014) found an even greater number with $60 \%$ of the

4 students surveyed using their own devices to support their learning. Both of these studies found

5 that another $20-30 \%$ of students who were surveyed owned mobile devices but at that time, they

6 did not use them to support their own learning. Welsh \& France (2012) suggest that this may be

7 because students do not recognise the potential of the devices that they own and that perhaps with

8 some guidance from staff, students may be more willing to use their own devices.

10 In light of findings to date, the overall aim of this research is to investigate how students feel about

11 using their own mobile devices to support their learning in the field following an experience of using

12 an institution-owned device.

\section{Methodology}

Questionnaires and focus groups were employed as a mixed-methodological approach to gather quantitative and qualitative data about students' perceptions of using BYOD to support field learning. The questionnaire and focus group questions were approved by the University of Chester Learning and Teaching Institute Research Ethics Committee and participants were able to withdraw from the research at any time. The student participants were attendees of one of six fieldtrips; five from the University of Chester (Geography) and one from the University of Reading (Biology). department-owned Apple iPad 2 devices to support their learning (their experiences are reported in Welsh et al., 2015). 
1 A total of 169 questionnaire responses was collected. Following on from the experience of using institutionally-owned devices, students were asked one of two open questions about BYOD in their post-fieldtrip questionnaire;

4 Q1: How would you feel about using your own Smartphone or iPad during future fieldwork? or

Q2: How would you feel about using your own device during future fieldwork?

Open questions were used to elicit detailed, in-depth responses from students (Patton, 2005) rather than selecting fixed responses. They were phrased slightly differently in the post-fieldtrip questionnaires used, however they essentially ask the same question and the responses were amalgamated.

169 students across first, second and third year of undergraduate programme opted to respond to the questionnaire of which $46 \%$ were female, $53 \%$ male (1\% no data) and $91 \%$ were aged between 18-21.

Thematic analysis was employed (Guest, MacQueen \& Namey, 2011) to analyse the questionnaire data whereby the researchers familiarised themselves with the data, generated initial codes, searched for themes within codes and finally reviewed and named themes. The themes that were explored in this paper were; iwillingness to use their own device for fieldwork ii) benefits of BYOD iii) challenges of BYOD in the field iv) preference for BYOD or institutional provision.

\subsection{Focus groups}

In addition to the questionnaire responses, 11 focus groups were conducted to enable students to offer more in-depth, richer qualitative responses than those given in the questionnaires (Kneale, 2001). Focus groups were conducted by a single facilitator at the end of each field course and students self-selected to opt into the focus group. The focus groups typically lasted 5-10 minutes; the average group size was 6 people with a range of 3-10 (Table 1). Student responses were 
1 recorded and reported anonymously so that the students were free to express their views.

2 Quotations from responses to the question 'Are there any issues or advantages of using your own

3 device in the field?' in the focus groups have been used to highlight some of the key themes that

4 emerged from this research.

\section{$5 \quad$ 3. Results}

6 The results from the questionnaire are presented quantitatively followed by discussion of qualitative

7 responses given in both the questionnaire $(n=169)$ and eleven focus groups.

\section{$8 \quad 3.1$ Student willingness to use their own device for fieldwork}

9 Students were then asked if they would be willing to use their own mobile device (e.g. smartphone/tablet/mp3 player) as a data collection tool during future fieldwork. Of the 169 questionnaire responses, $79 \%$ stated that they would be willing to use their own device and $21 \%$ of students stated that they would not be willing to use their own device for data collection during fieldwork, the reasons for which are outlined in section 3.3.

\subsection{Benefits of using BYOD}

Across the focus group and questionnaire data, the students who were willing to use their own devices discussed a range of reasons why they preferred to use their own device.

i. Familiarity with the device was a common theme throughout with $14 \%(n=169)$ stating that using their own device would be beneficial to their learning as they would be more familiar with the device. The assumption is that this would save them time and effort in learning how to operate an unfamiliar device, therefore allowing them to focus on the learning task at hand. Students suggested that: apps on it" (Devon, FG, 2013)

"I would prefer to use my own smartphone/iPad. More familiar with functions my email

+ iCloud system is linked to my devices already" (Naples, FG, 2012). 
"I would use it better because I know exactly how to use it." (Devon, Q, 2012). Another student further supported these ideas by suggesting using his/her own device would be less "stressful to operate" (Devon, Q, 2012) than an institutional device.

ii. Personalisation of the device was considered to be a benefit with of students $7 \%$ ( $n=169)$ stating that using their own device would allow them to personalise their devices to their own learning needs and have access to their own data:

"My own would be better as can have personal apps to keep sharing real time research and use to actually annotate all my work rather than share with other people." (Iceland, Q, 2013).

"My own personal information can be stored meaning that it's easily accessible" (Devon, Q, 2012)

"You access data whenever you want" (Devon, Q, 2012).

“It was easier to email on your own device as well cos you've already got your account set up." (NYC, FG, 2012)

\subsection{Challenges of using BYOD}

The main challenges of using BYOD cited by students were damage $(22 \%, n=169)$, inequality $(9 \%$, $n=169)$, requiring more support $(4 \%, n=169)$ and concerns about battery life during a day in the field $(2 \%, n=169)$.

\subsubsection{Damage}

Damage was the main theme raised by $22 \%(n=169)$ of the total participants including those who had expressed a willingness to use their own device as well as those who had stated they would not be willing to use their own device in the field. Some students were concerned about damaging 
institution-owned devices in the field and would worry less about damaging their own device. However, others were more worried about damaging their own device. For example:

"[The device] is my own item so it is my own responsibility" (Devon, Q, 2012).

"I would be less concerned [using my own device] than using a University iPad as losing your own [device] would be at your own risk" (New York, Q, 2012).

"I would be concerned about dropping it etc. but if a protective case was provided then it [using my own device] would be a possibility" (Iceland, Q, 2013).

"I wouldn't want to take my phone out if it was raining" (Devon, Q, 2012)

"Wouldn't use my smartphone because of rain and being near the water" (Devon, Q, 2012).

"I would prefer to use one of the departments due to potential damage" (Naples, FG ,2012)

"I am happy to use my iphone as it is easier to handle than an ipad. If it was my own ipad I would worry about damage or theft (rain also)" (Devon, Q, 2013)

In terms of the student concerns with using their own device, responses from the questionnaire and focus group data suggest that though students would be happy to use their device for some parts of the fieldwork, they may not be willing to use their device all of the time. During the Naples Focus group, when asked if students would be prepared to bring their own devices the students immediately posed conditions to this option; focusing on the location and nature of the activity. Students were more reluctant to take their equipment into the field for a physical geography activity that involved the potential for rain or high-impact damage due to terrain. From all of the Focus Group responses, the main reason given for not being prepared to use the student's own devices during fieldwork is concerns about damage to their device:

"I was scared about dropping my iPad" (Devon, FG, 2013)

"I would rather not [use my own device] as they are so fragile" (Iceland, Q, 2013).

However, with regards to using smartphones, another student suggested that perhaps the students should not be too concerned using their device for an additional purpose: 
"I use it every day so I don't see how it would make any difference cos it was geography related" (Devon, FG, 2013)

"I would feel more comfortable using my own however again would be concerned over breaking but it would be no different to concerns I would have using outside of fieldtrips too" (Devon, Q, 2012).

2012)

$21 \%(n=169)$ of students stated that they would not want to use their own device and this was largely due to concerns about damage.

\subsubsection{Inequality}

Inequality was the second largest negative theme mentioned by questionnaire participants. 9\% $(n=169)$ of students mentioned that they either did not own a device or BYOD would lead to inequality between those who have devices and those who do not own devices. Qualitative data showed that students expressed concern over equality suggesting that;

"not everyone owns these [own devices] so I can't see it [BYOD] happening" (Naples, Q, 2012) "Don't think people should be required to use their own devices as not everyone owns one" (Devon, Q, 2012).

"I don't have a ipad or smartphone so this could be a problem" (Devon, Q, 2013)

\subsubsection{Group Work}

Although not identified as a theme in the quantitative data, 'group work' was discussed throughout the qualitative data. There were conflicting views from students about whether or not BYOD would be better than institutional devices for fieldwork, but the dominant theme suggested that students did not think BYOD would be good for group work. Some students were concerned that the BYOD concept would not be conducive to effective group work;

"[The device provides] easy access to endless information, but does not promote teamwork if working in a group" (Devon, $Q, 2012)$ 
1 This conveys a concern that the owner might dominate the device rather than sharing equally. One

2 student went further and commented that:

3

“it would be weird to pass somebody's phone around. I wouldn't feel comfortable for them to go off and borrow it to go on fieldwork" (Naples, FG, 2012).

Resource collation was also considered to be an issue when using BYOD as it; "would be hard to collate resources when working in groups, not everyone has a device or has all the apps" (Naples, Q, 2012).

\subsubsection{Distraction}

Very few students $(2 \%, n=169)$ in the questionnaire data mentioned being distracted by using their own devices for fieldwork yet this was discussed in the qualitative responses from the focus groups. Of the small number of students who did discuss distraction in the qualitative responses, their general view was that using their own devices could be potentially distracting;

"I would be okay about [using] it, however, I would get too distracted with the access to Facebook, Twitter and texting" (Naples, Q, 2012),

"It would be good to use my own but I would get distracted easily" (Devon, Q, 2012),

"It's easier to get distracted, with texts and stuff like that." (Devon, FG, 2013).

All students within the Spain (2012) focus group agreed that the iPads they had access to through the university were less distracting than their personalised devices, which may have games on them. However one student countered this view and suggested that their own device would not be as distracting if they were using it for work purposes:

"I think if I was out there [in the field] for work I wouldn't be tempted by games" (Devon, FG, 2013).

It also made some of the students consider how their own devices can be used in a different way to that which they are used to: 
"In a way it did make me think 'iPhones aren't just for internet and facebook and games', they are actually quite useful and it did make me think maybe my next phone should be an iPhone" (Iceland, FG, 2012)

\subsection{Preference for BYOD or institutional provision of mobile technologies}

The preference for using an iPad (or tablets) versus a smartphone was mixed. One student suggested that they were:

"very keen [to use a device during fieldwork] but wouldn't use a smartphone but would definitely use an iPad. My own would be better as can have personal apps to keep sharing real time research and use to actually annotate all my work rather than share with other people" (Iceland, Q, 2013).

Other students expressed a preference for using a smartphone, particularly during urban fieldwork or in rugged landscapes where there was the greatest danger from damage or theft. In these situations, students felt that they could put a smartphone in a bag or pocket more easily than an iPad due to the differences in size. They felt as though being able to carry the smartphone device in their pockets would reduce the likelihood of dropping and damaging the device or carrying it around conspicuously and risking the device being stolen. Some students also felt the devices (despite having very similar capabilities) had different roles to play in the fieldwork experience;

"smartphones are personalised to the person, not the subject, so the content of the phone may include games and additional distractions. The university iPad [is] personalised to geography, whereas my phone is personalised to me" (Naples, FG, 2012).

"I was a bit worried, cos as we were doing our presentation it just started to rain and I had my iPad out and I only have a little flimsy cover, so I had to hide it. So I suppose that was a bit of a risk cos I don't have insurance on it. The uni ones have like a hard cover on them, in case you dropped it." (Iceland, FG, 2012)

Using the students' smartphones or other devices when working in a group has the additional complication of how to share data. If students have different devices then the compatibility of the devices may vary. Some devices may not have the same accessibility to certain apps; the difference 
1 between Apple, Android and Windows. The general consensus of the Naples focus group agreed with one student, who said; "if you're all using part of an iPad, everyone's got the same advantage, whereas if you're all using your own things... it's not fair" (Naples, FG, 2012).

\section{Discussion}

\subsection{Student willingness to use their own device}

To some extent, the level of willingness of students to use their own device in a classroom or fieldwork setting could be considered to be a challenge, particularly if there are students who are unwilling to use their own device. The results presented within this paper show that whilst $79 \%$ ( $n=169)$ of students are willing to use their own device for fieldwork, $21 \%(n=169)$ are not willing to use their own device. The results presented here identify that there are a number of reasons why students are not willing to use their own device, with the main theme of concern being damage during fieldwork. Over one fifth of the responses stated that there were conditions that would be imposed about when and how they would be willing to use their device in the field. However, it is worth noting that the student's concern for damaging equipment is not limited to student owned devices but also institutionally owned devices. Welsh et al. (2015) found that $35 \%$ of students who had used institutional iPad devices were concerned about damaging the devices in some way. A lack of willingness for students to use their own device will require practitioners to make BYOD activities optional. It may be good practice to offer non-digital alternative activities or provide students who are unwilling to use their own device with an institutional device. This could create additional work for the practitioner who is devising the BYOD exercise. Rather than thinking of BYOD in terms structured mandatory exercises without suitable alternatives, BYOD could be considered to offer students a choice about how they learn and when they learn and be considered to "enhance" their flexible learning opportunities (Peat and Franklin, 2002) thereby putting 
1 pedagogy at the forefront of teaching design rather than allowing technology to be the focus of the

2 learning activity.

3

\section{$4 \quad 4.2$ Benefits of BYOD in the field}

5 The two key benefits of using BYOD that were identified by the students are familiarity with the device and personalisation of the device including being able to access their own data after the fieldwork. Familiarity is widely regarded as one of the key benefits of BYOD in a range of contexts (Fiorenza, 2013, Ghosh, Gajar, and Rai, 2013, Stevenson \& Wright, 2015). In a learning context, students can focus on the learning activity rather than focusing on how the technology works. Focusing on the technology rather than the pedagogy is a common complaint amongst practitioners who use technology to support learning activities during fieldwork and particularly amongst practitioners who are reluctant to use technology for fieldwork (Fletcher et al., 2007; Welsh et al., 2013). BYOD can circumvent practitioners' frustrations with technology by allowing the limited time available in the field to focus on student learning. France et al. 2015 suggest that smartphones and iPads are a key part of a student's Personal Learning Environment (Van Harmelen, 2006) as they are able to personalise the devices to suit their own learning style which could subsequently lead to increased motivation and engagement (Stavert, 2013).

\subsection{Challenges of BYOD in fieldwork}

One of the key findings of this research is that the majority of challenges faced by using BYOD in the field are different to those faced in a classroom. Santos (2013) outlines the main challenges of BYOD in the classroom as the need for good network connectivity, the importance of network security when connecting student devices to the university Wi-Fi, increased IT support is a requirement of BYOD, disruption in the classroom and inequality between students (difference device capabilities). However, within the results presented here, network security and increased IT support are not mentioned by students as challenges of using BYOD, though perhaps practitioners' perspectives may 
1 differ particularly with regards to increased required IT support. The results presented within this paper identify that damaging their own device is a concern for students implementing BYOD in the field, yet damage of devices is not mentioned as a challenge in any previous research about BYOD in the classroom, which is likely to be a function of classroom environments being considered safer than outdoor rugged terrain where damage is more likely to occur to a device. (2013), the following sections discuss whether BYOD challenges in the classroom are the same as those found here.

\section{9}

\subsubsection{Network connectivity}

Network connectivity is an issue in the field as it is in the classroom, however this is not a challenge confined to BYOD but mobile learning in general as outlined by Welsh et al. (2015). In some ways, network connectivity may be arguably less of a challenge in the field than in a classroom. This is because practitioners generally expect and plan for a poor/limited wi-fi or $3 \mathrm{G}$ signal in fieldwork environments and will be more likely to be prepared to ensure their activities include offline apps only. However, in a classroom, poor network connectivity ought to be less expected (though in practice, this is not always the case) and practitioners often do not consider an alternative activity if the network signal is poor.

\subsubsection{Network Security}

Network security is not a significant issue for using BYOD in the field; whether students use their own device or an institutional device, they do not connect to the institution's network but do connect to external Wi-Fi and 3G. This presents no greater security risk than it would if the students were to connect their devices for personal reasons (such as accessing social media). However augmenting their general awareness about network security would be of benefit to students both in a classroom and fieldwork context. 


\subsubsection{Increased IT support needed}

In terms of additional IT support, this was not an issue raised by the students within this research. No additional support is required for BYOD than for m-learning. Arguably, BYOD in the field reduced the amount of IT support needed as students had pre-existing knowledge of how to use their device.

\subsubsection{Disruption in the classroom}

There is a feeling that mobile phones in particular are seen as disruptive to students in lectures (Geist, 2011) yet many studies have outlined the positives that can be achieved when mobile devices are brought into a classroom (e.g. Scornavacca et al. 2009, Welsh \& France, 2012). Educating students on acceptable mobile device usage during lectures is the key to success with BYOD in a classroom (Burns \& Lohenry, 2010) and this is also true for fieldwork. However, there are likely two main reasons why the findings presented here suggest that BYOD as a distraction may be a less likely a challenge for fieldwork. Firstly, due to the aforementioned poor Wi-fi or $3 \mathrm{G}$ connection that students often experience in remote or rural locations, their access to social media and other distractors may be limited. Secondly, it is likely that because the students are actively participating in the fieldwork (i.e. writing observations, collecting data) rather than passively listening to lectures, their level of engagement may be higher and the need to distract themselves with their mobile device may be reduced. This research supports McNeill et al. (2011) who state "that this generation of students prefer receiving information rapidly[... ]have a low tolerance for lectures; prefer active rather than passive learning and rely heavily on communication technologies to access information" (p.2). It is likely that the active learning that takes place during fieldwork means that they focus on the task itself rather than being distracted by the technology. The findings outlined here support the idea that distraction via students' own devices generally occurs when students are passively participating in teaching sessions rather than when they are actively learning (Chickering \& Gamson, 1987). 
2 The results presented within this paper show that students feel as though inequality is a challenge for BYOD demonstrating that similarly to a classroom environment (Santos, 2013), inclusivity and inequality is also one of the greatest challenges for fieldwork. Though smartphones are considered "almost ubiquitous" (Welsh \& France, 2012, p.46) across the population, various studies (e.g. Lerczak, 2014; Welsh et al., 2015) have demonstrated that between 80 and $90 \%$ of students own a smartphone, there are still $10-20 \%$ of students who do not own a device suitable for enhancing their learning in a classroom or in the field. Overall the results presented here suggest that the students prefer using their own smartphones for personalised learning but believe tablets/iPads provided by the institution promote equality for all students. The qualitative results presented here indicate that students are more concerned with compatibility of devices and differences in software rather more than the seemingly greater issue that not all students have their own mobile devices. The student participants raised concerns about students who borrow spare university iPads having a greater advantage due to having suitable software installed than if they used their own device. This could perhaps be circumnavigated by using institutionally-written apps specific to field courses or only using apps that are available across all platforms. However for inquiry based fieldwork in small groups, BYOD approach would allow students to download and use their preferred apps that are required to fulfil the goals of their own personal research. Perhaps practitioners are focusing on the wrong aspect of inequality (i.e. own a device versus do not own a device) and should instead focus on how to educate students pre-fieldwork about suitable apps that they may want to download in advance of the fieldwork.

\subsubsection{Group Activities}

Interestingly, BYOD has been cited by Welsh \& France (2012) as being well suited to group work, largely because usually at least one student in a group would have their own device which could then be shared. However, the findings presented within this research paper suggest that students 
1 are actually concerned about the impact BYOD may have on team work or group work, largely due

2 to perhaps a single member of the group commandeering the mobile device thereby marginalising

3 students who may have been previously included. However, it is pertinent to note that this problem

4 also applies to institutionally owned devices and is not exclusive to BYOD. There is somewhat of a mismatch here between student and practitioner thinking and highlights the value of perception studies from the point of view of both the student and practitioner. Other concerns about group work highlight the difficulties of sharing data between devices though this is somewhat less of a problem in 2016 due to functions and software such as Apple Airdrop, iCloud, OneDriveand

9 Dropbox.

\subsubsection{Damage}

Damage of student's own devices is a key area of concern and partially explains why $21 \%(n=169)$ of students indicated that they would be unwilling to use their own device. Though BYOD classroom based studies are limited in availability and scope, Hamza and Noordin (2013) found that only 5\% of students were concerned about damage or loss. This suggests that perhaps students are less willing to use their devices out in the field due to poor weather, rugged terrain or potential theft of the devices than they would if they used them in the classroom.

\section{Conclusions}

There are two main benefits of BYOD in the field as identified by students; familiarity with the device to enable them to focus on their learning and the ability to personalise their learning space. These are two significant educational benefits that facilitate active learning in the field (Whalley et al. , 2016) classroom (e.g. the need for good network connectivity, the importance of network security when 
connecting student devices to the university Wi-Fi, increased IT support is a requirement of BYOD, disruption in the classroom and inequality between student devices (Santos, 2013)) apply to using BYOD in the field. Here we have identified that the key challenges for using BYOD in the field (as perceived by students) are:

○ Lack of willingness of all students to use their own devices for fieldwork learning

- Concerns about potential damage to devices

- Concerns about the impact BYOD may have on group work

- Inequality between different devices and between students who have smart devices and those who do not.

The main challenge which features in both a classroom environment and a fieldwork environment is inequality. The forthcoming shift to BYOA (Bring Your Own App) or Bring Your Own Everything (BYOx) (Rossi, 2014) may go some way to address differences in the performance level of student's own devices both in the field and classroom. Practitioners should try to encourage students to find apps that they are likely to use for fieldwork learning (e.g. "find a geotagging app that you can download to your own device"). Welsh \& France (2012) suggested that BYOD would be best used for group activities. However, the student perceptions presented here suggest that some students do not believe this to be true.

\section{Acknowledgements}

We would like to thank all of the students who participated in the surveys and focus groups. . The 3year National Teaching Fellowship Project 'Enhancing Fieldwork Learning' was funded the Higher Education Academy.

\section{References}

Afreen, R. (2014). Bring Your Own Device (BYOD) in Higher Education: Opportunities and Challenges. International Journal of Emerging Trends \& Technology in Computer Science, 3(1). 


\footnotetext{
Alberta Education, (2012) Bring your own device: A guide for schools. Alberta Education. Retrieved from http://education.alberta.ca/admin/technology/research.aspx

Ballagas, R., Rohs, M., Sheridan, J. G., \& Borchers, J. (2004). Byod: Bring your own device. In Proceedings of the Workshop on Ubiquitous Display Environments, Ubicomp.

Bedall-Hill, N. (2011). Postgraduates, field trips and mobile devices. In J. Traxler \& J. Wishart (Eds.), Making mobile learning work: Case studies of practice (pp. 18-22). ESCalate HEA Subject Centre for Education. Retrieved September 3, 2011, from http://escalate.ac.uk/8250

Boyle, A., Maguire, S., Martin, A., Milsom, C., Nash, R., Rawlinson, S., \& Conchie, S. (2007). Fieldwork is good: The student perception and the affective domain. Journal of Geography in Higher Education, 31(2), 299-317.

Burns, S. M., \& Lohenry, K. (2010). Cellular phone use in class: Implications for teaching and learning a pilot study. College Student Journal, 44(3), 805.

17 Chickering, A. W., \& Gamson, Z. F. (1987). Seven principles for good practice in undergraduate

18 education. AAHE bulletin, 3,7 .
} 
Conole, G., de Laat, M., Dillon, T., \& Darby, J. (2008). Disruptive technologies, pedagogical innovation. What's new: Findings from an in-depth study of students' use and perception of technology.

Computers \& Education, 50(2), 511-524.

diFilipo, S. (2013). The Policy of BYOD: Considerations for higher education. EDUCAUSE Review March/April, 60-61.

Fang, B. (2009). From distraction to engagement wireless devices in the classroom. EDUCAUSE Quarterly, 32(4). Retrieved $9^{\text {th }}$ July 2015 from http://www.educause.edu/ero/article/distractionengagement-wireless-devices-classroom

Fiorenza, P. (2013). Mobile technology forces study of bring your own device. Public Manager, 42(1), 12-14.

Fletcher, S., France, D., Moore, K. \& Robinson, G., (2007). Practitioner Perspectives on the Use of Technology in Fieldwork Teaching. Journal of Geography in Higher Education, 31(2), 319-330.

France, D., Powell, V., Mauchline, A. L. Welsh, K., Park, J, Whalley, W. B., \& Rewhorn, S. (2016) Ability of students to recognize the relationship between using mobile apps for learning during fieldwork and the development of graduate attributes, Journal of Geography in Higher Education, 40(2), 182-192

France, D., Whalley, W. B., \& Mauchline, A. L. (2013). Using mobile devices to enhance undergraduate field research. Council of Undergraduate Research Quarterly, 34, 38-42.

Fuller, I., Edmondson, S., France, D., Higgitt, D., \& Ratinen, I. (2006). International perspectives on the effectiveness of geography fieldwork for learning. Journal of Geography in Higher Education, 30(1), 89-101.

Geist, E. (2011). The game changer: Using iPads in college teacher education classes. College Student Journal, 45(4), 758-769.

Ghosh, A., Gajar, P. K., \& Rai, S. (2013). Bring your own device (BYOD): Security risks and mitigating strategies. Journal of Global Research in Computer Science, 4(4), 62-70.

Grant, P., \& Basye, D. (2014). Personalized learning: A guide for engaging students with technology. International Society for Technology in Education.

Guest, G., MacQueen, K. M., \& Namey, E. E. (2011). Applied thematic analysis. Sage.

Hamza, A., \& Noordin, M. F. (2013). BYOD usage by postgraduate students of International Islamic University Malaysia: an analysis. International Journal of Engineering Science Invention, 2(4), 1420.

Jarvis, C. and Dickie, J. (2010) 'Podcasts in support of experiential field learning', Journal of Geography in Higher Education, 34, pp. 173-86.

Johnson, L., Adams, S., and Cummins, M. (2012). The NMC Horizon Report: 2012 Higher Education Edition. Austin, Texas: The New Media Consortium ... 
Kern, E. L., \& Carpenter, J. R. (1984). Enhancement of Student Values, Interests and Attitudes in Earth Science through a Field-Oriented Approach.Journal of Geological Education, 32(5), 299-305.

Kneale, J. (2001) Working with groups. In Lamb, M. \& Dwyer, C. (Eds.) Qualitative Methods for Geographers issues and debates. Oxford University Press, New York.

7

Lerczak, A. (2013) Student Perceptions of Using Mobile Technologies in Higher Education Fieldwork. Unpublished Dissertation.

Maskall, J., and Stokes, A. (2008). Designing Effective Fieldwork for the Environmental and Natural Sciences. pp77. HEA GEES Subject Centre.

McNeill, M., Ming Diao, M., \& Gosper, M. (2011). Student uses of technology in learning: two lenses. Interactive Technology and Smart Education, 8(1), 5-17.

Miller, S., Welsh, K.E. (submitted) BYOD in Higher Education: Opportunities and Challenges. Journal of Geography in Higher Education

Murphy, A. (2013). Open educational practices in higher education: institutional adoption and challenges. Distance Education, 34(2), 201-217.

NUS (2010) Student perspectives on technology - demand, perceptions and training needs. Accessed on $21^{\text {st }}$ March 2016 from:

http://www.hefce.ac.uk/media/hefce/content/pubs/2010/rd1810/rd18_10.pdf

Parsons, D., \& Ryu, H. (2006, April). A framework for assessing the quality of mobile learning.

In Proceedings of the International Conference for Process Improvement, Research and Education (pp. 17-27).

Patton, M.Q. (2005) Qualitative Research. John Wiley \& Sons, Ltd

/

Rossi, B. (2014) Forget BYOD: The rise of BYOx. Retrieved $1^{\text {st }}$ April 2016 from:

http://www.information-age.com/technology/mobile-and-networking/123457803/forget-byod-risebyox

Pfoutz, J. (2012). Advantages and Disadvantages of Bring Your Own Device. Secure

Connexion. Retrieved 10 August, 2015, from

https://secureconnexion.wordpress.com/2012/08/27/advantages-and-disadvantages-of-bring-yourown-device-byod-in-education-mini-whitepaper/

Peat, M., \& Franklin, S. (2002). Supporting student learning: the use of computer-based formative assessment modules. British Journal of Educational Technology, 33(5), 515-523. 
Sainsbury’s Bank (2014). Full-time students in higher education have as much as $£ 4.3$ billion of belongings away from the home. Accessed 26 February 2016. Available at:

http://sainsburysbankmedia.co.uk/full-time-students-in-higher-education-have-as-much-as-4-3-

billion-of-belongings-away-from-the-home/ [

5

Santos, I. M. (2013, October). Use of students' personal mobile devices in the classroom: Overview of key challenges. In World Conference on E-Learning in Corporate, Government, Healthcare, and Higher Education (Vol. 2013, No. 1, pp. 1585-1590).

Scornavacca, E., Huff, S., \& Marshall, S. (2009). Mobile phones in the classroom: if you can't beat them, join them. Communications of the ACM, 52(4), 142-146.

Stavert, B. (2013). Bring your own device (BYOD) in schools 2013 literature review. Eveleigh, New South Wales: Department of Education and Communities. Retrieved from https://www.det.nsw.edu.au/policies/technology/computers/mobiledevice/BYOD_2013_Literature_Review.pdf

Steiner,F. (2016). BYOD, ready or not!. [online] Available at: http://edquarter.com/Article/byod-readyor-not [Accessed 29 Aug. 2017].

Stevenson, S. \& Wright, B. (2015). Back pocket learning - enabling 'digital natives' to use smart devices to ensure understanding of the threshold concepts of journalism. In Middleton, A (Ed), Smart Learning (pp. 138-145). Sheffield, United Kingdom: Media-Enhanced Learning Special Interest Group and Sheffield Hallam University, 2015.

Swan, K., Hooft, M. V. T., Kratcoski, A., \& Unger, D. (2005). Uses and effects of mobile computing devices in K-8 classrooms. Journal of Research on Technology in Education, 38(1), 99-112.

Van Harmelen, M. (2006, July). Personal Learning Environments. In ICALT (Vol. 6, pp. 815-816).

Welsh, K., \& France, D. (2012). Spotlight on... Smartphones and fieldwork.Geography, 97, 47.

Welsh, K. E., Mauchline, A. L., Powell, V., France, D., Park, J. R., \& Whalley, W. B. (2015). Student perceptions of iPads as mobile learning devices for fieldwork. Journal of Geography in Higher Education, 39(3), 450-469.

Whalley, W.B., France, D., Mauchline A.L., Welsh, K. \& Park, J. (2016) Everyday student use of iPads: A vade mecum for students' active learning. Proceedings of the 2nd International Conference on the use of iPads in Higher Education, (ihe2016), Cambridge Scholars Publishing.

Woodcock, B. Middleton, A. Nortcliffe, A (2012) Considering the Smartphone Learner: an investigation into student interest in the use of personal technology to enhance their learning. Student Engagement and Experience Journal Volume 1, Issue 1 